\title{
Laparoscopic Nissen fundoplication and gastrostomy for a giant hiatal hernia in an infant with situs inversus totalis
}

\author{
Ramnik V Patel, ${ }^{1,2}$ Paul Jackson, ${ }^{3}$ Paolo De Coppi, ${ }^{4}$ Joseph Curry ${ }^{3}$
}

${ }^{1}$ Department of Paediatric Urology, University College London Hospitals NHS Foundation Trust, London, UK ${ }^{2}$ Department of Paediatric Urology, Great Ormond Street Children Hospital NHS Trust, London, UK

${ }^{3}$ Department of Paediatric Surgery, GOSH, London, UK ${ }^{4}$ Department of Paediatric Surgery, GOSH and ICH, London, UK

\section{Correspondence to} Ramnik V Patel,

ramnik@doctors.org.uk

\section{CrossMark}

To cite: Patel RV, Jackson $P_{\text {, }}$ De Coppi P, et al. BMJ Case Rep Published online:

[please include Day Month Year] doi:10.1136/bcr-2013202764

\section{DESCRIPTION}

A case of giant hiatal hernia $(\mathrm{HH})$ associated with severe gastro-oesophageal reflux disease (GORD) treated by laparoscopic Nissen fundoplication and gastrostomy in an infant with situs inversus totalis (SIT) is reported highlighting the challenges we encountered in this case. The 8-month-old infant was previously diagnosed with SIT. He had a giant $\mathrm{HH}$ and presented with chronic severe GORD with repeated aspiration pneumonia and failure to thrive despite full antireflux medications and nasojejunal tube feeding (NJT) (figure 1). After thorough preoperative evaluation including echocardiogram, we performed laparoscopic Nissen fundoplication by modifying the operative technique adopting a mirror image of various port placements. The reverse anatomy orientation was practiced preoperatively by the surgical team in view of the rarity of the presentation. This allowed us to orient to the reverse anatomy in vitro and get used to this special situation in advance. The laparoscopic Nissen fundoplication was performed using five ports, reversed from our original positions. At laparoscopy, complete mirror image reversal of the internal organs was confirmed. We then performed a Nissen fundoplication and gastrostomy uneventfully. He is asymptomatic and thriving well at 6-year follow-up. Laparoscopic Nissen fundoplication is the gold standard for the treatment of severe GORD in children and is one of the commonly performed abdominal procedures. However, presentation of GORD in patients with SIT is rare and poses diagnostic and therapeutic challenges. A reverse mirror image orientation to each step of the operation is a real challenge during the procedure. ${ }^{1-3}$ Laparoscopic Nissen fundoplication can be performed safely by an experienced team with a shorter hospitalisation, reduced discomfort and cosmetic advantages.

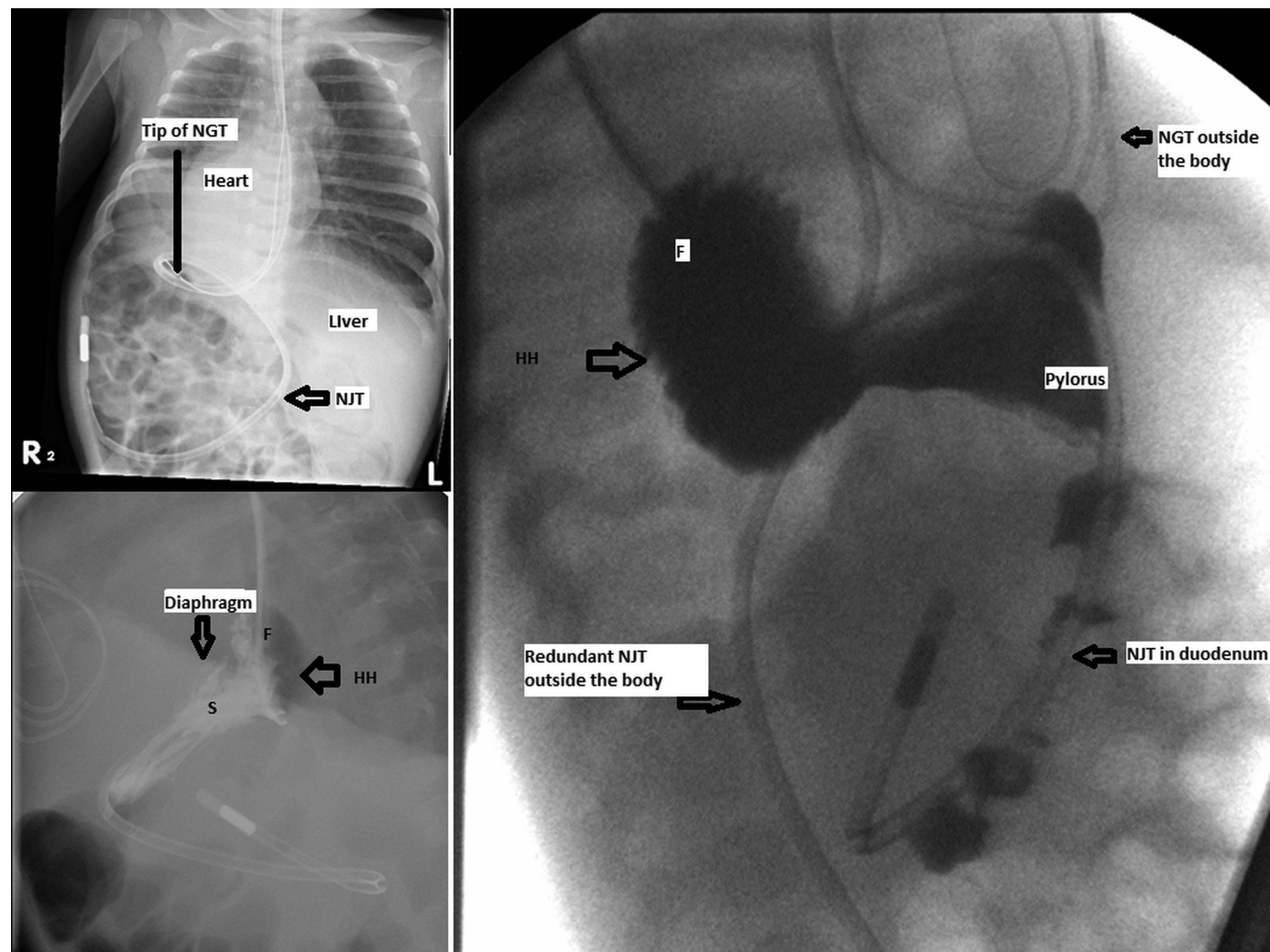

Figure 1 Babygram showing situs inversus totalis (SIT) with nasojejunal feeding tube in situ (NJT) and upper gastrointestinal contrast showing giant hiatal hernia $(\mathrm{HH})$ with severe gastro-oesophageal reflux disease (GORD). $\mathrm{F}$, fundus of stomach; NGT, nasogastric tube; $S$, stomach; $P$, pylorus. 


\section{Learning points}

- Thorough preoperative evaluation to exclude associated anomalies, differences in presentation, difficulties in diagnosis and the necessity of reverse orientation during laparoscopic procedure with its rehearsal preoperatively is very helpful.

- The use of advanced laparoscopic techniques is highly adaptable to unusual anatomy and complete reversal of orientation of the 'handedness'.

- Laparoscopic hiatal hernia (HH) surgery is feasible in patients with situs inversus totalis (SIT) with rehearsal of reverse orientation preoperatively.
Contributors All the authors have made substantial contributions to the conception and design of this article, search of literature, the acquisition, analysis and interpretation of the data, in drafting the article or revising it critically for important intellectual content, and to the final approval of the version to be published.

Competing interests None.

Patient consent Obtained.

Provenance and peer review Not commissioned; externally peer reviewed.

\section{REFERENCES}

1 Tsung A, Feliz A, Kane TD. Laparoscopic Nissen fundoplication in an infant with situs inversus. J Laparoendosc Adv Surg Tech A 2007;17:698-700.

2 Hoang CD, Bakman YG, Ikramuddin S, et al. Situs inversus totalis: giant hiatal hernia repair by laparoscopic Collis gastroplasty and Nissen fundoplication. Surg Endosc 2004;18:345-9.

3 Koo KP. Laparoscopic Nissen fundoplication in a patient with situs inversus totalis: an ergonomic consideration. J Laparoendosc Adv Surg Tech A 2006;16:271-3.

Copyright 2014 BMJ Publishing Group. All rights reserved. For permission to reuse any of this content visit http://group.bmj.com/group/rights-licensing/permissions.

BMJ Case Report Fellows may re-use this article for personal use and teaching without any further permission.

Become a Fellow of BMJ Case Reports today and you can:

- Submit as many cases as you like

- Enjoy fast sympathetic peer review and rapid publication of accepted articles

- Access all the published articles

- Re-use any of the published material for personal use and teaching without further permission

For information on Institutional Fellowships contact consortiasales@bmjgroup.com

Visit casereports.bmj.com for more articles like this and to become a Fellow 